and magmatic cycles of the Andean syncline, tertiary and quaternary vulcanism and the magmatic provinces in the Andes.

A further meeting is being planned for December 1961, and will be held in Santiago de Chile, to consider reports to be presented by the scientists participating in the meeting in Buenos Aires and to elaborate further and develop the specific projects in each scientific field.

In the meantime, the Unesco Scientific Office in Montevideo will start compiling a bibliography of research done on the Andes, and collecting the names of acientists who have been active in that field, or who, by their training, are likely to be interested in participating in any of the activities planned for the International Andean Year.

Further information on this project can be obtained from Dr. A. Establier, Centro de Cooperaciôn Científica de la Unesco para América Latina, Boulevard Artigas 1320, Montevideo, Uruguay.

V. Deulofeu

\title{
SOLAR VARIATIONS, CLIMATIC CHANGE AND RELATED GEOPHYSICAL PROBLEMS
}

Un NDER the above title, a symposium was arranged by the New York Academy of Sciences, through the Academy's Section of Geological Sciences and its Division of Oceanography and Meteorology, in cooperation with the American Meteorological Society. The meetings were held in New York during January 24-28. The papers given at the symposium are to be published by the Academy in a fortheoming volume of its Annals.

Understandably, the United States provided about four-fifths of the sixty or so participants who offered papers or contributed to the discussions, but a number of workers active in the fields covered by the symposium were present from Canada, the United Kingdom, Holland, Germany and Hungary. Swedish, Russian and Australian contributions had been invited, but their authors were unable to be present. Abstracts of the papers were provided and the meeting as a whole was admirably organized. The generous hospitality of the New York Academy of Sciences was indeed a feature.

The organization of the conference and the arrangements for overseas visitors were largely in the hands of Dr. Rhodes W. Fairbridge, professor of geology at Columbia University, to whom indeed a great part of the success of the meeting was due. Dr. Fairbridge's arguments for the relationship of changes of sea-level, great and small, to the fluctuations of climate which have affected and continue to affect the volume of the Earth's ice-sheets and glaciers, have become widely known (cf. his recent article in Scientific American, 202, No. 5, 70; 1960). A fuller statement has now been published in Physics and Chemistry of the Earth, 4 (Pergamon Press, 1961). Developing as they do from his earlier work on the eustatic changes shown on the cosst of West Australia, they integrate a vast amount of carefully assembled field evidence on a world-wide scale and, cautiously yet persuasively presented, they will be found acceptable by many workers. Nevertheless, it can be agreed that we do not yet know enough about the other agencies that may have affected the volume of the hollows in which the oceans lie.

Climatic change is demonstrably a subject with exceptional ramifications, and the contributions of a great many scientists from differing disciplines are repeatedly called for. Accordingly, the scope of the symposium was enormously wide, beginning with six papers on solar physics under the chairmanship of Dr. Donald H. Menzel (Harvard University). Climatic effects potentially attributable to solar variation were discussed under the chairmanship of Dr. Sigmund Fritz, replacing Dr. H. Wexler, who could not be present. It is evident that the only effects of solar variation that are so far generally accepted are those observable in the extreme ultra-violet end of the solar spectrum, affecting the high atmosphere and the Earth's magnetic field, although some of the apparent relationships with atmospheric circulation patterns are sufficiently suggestive to justify further attention. Among a variety of papers on various aspects of the radiation balance and the general circulation, $H . H$. Lamb (Meteorological Office, Harrow) presented some of his recent work on displacements of the circulation pattern (cf. Geografiska Annaler, 1960). A further session was devoted to meteorological satellites. Dr. Helmut E. Landsberg (United States Weather Bureau) took the chair at a session entitled "Glaciology, Oceanography and Climatology"; here Dr. William L. Donn presented a summary of the EwingDonn theory of the ocean control of Quaternary climate (Science, 1958), unfortunately with insufficient time for discussion of a controversial topic in which many would gladly have joined. A preceding paper by Dr. T. N. V. Karlstrom (Coast and Geodetic Survey, Washington) on the glacial history of Alaska provided evidence manifestly difficult to reconcile.

With Dr. R. F. Flint (Yale University) in the chair, followed by Dr. E. S. Deevey (Yale University), palæoclimatology came under review, including several papers around the theme of palynology. Dr. E. H. Willis (University of Cambridge) commented on some of the Fenland evidence. Among the most interesting contributions was that of Dr. Calvin Heusser (Amerioan Geographical Society), who gave evidence for the approximate contemporaneity of Late- and Post-Glacial events in the Rockies and the Southern Andes. With Prof. F. E. Zeuner (University of London) in the chair, a final session was devoted to papers around the theme of "Climatic Change and Man". Archrological studies in the United States and in the Near East were noteworthy; Dr. Ralph Solecki's discussion of some of the preliminary findings at the Shanidar cave in Northern Iraq was of great interest, and attracted attention.

It will be evident from this brief summary that a remarkable diversity of papers came up for discussion. Throughout the symposium the impression prevailed that there are many who are still hopeful that some kind of periodicity will appear, based on such solar manifestations as we can observe. From others, dispiriting criticisms equally abound. Dr. Reid Bryson (University of Wisconsin), for example, has applied modern statistical methods to the analysis of tree-ring spectra and found that the usual sunspot cycles fail to appear. On the other hand, several 
contributors provided support for relationships between solar variations and the pattern taken by the general eirculation.

It became abundantly clear how large a number of investigators are patiently accumulating evidence of the amplitude, character, effects and especially the dating of climatic fluctuations all over the world. Speculations regarding the causes abound; supporters of each of the popular theories-solar variation, atmospheric turbidity, carbon dioxide, ozone, variations in the Earth's orbital elements - find their several gods alternately set up and cast down. Workers in one field find themselves unable to judge the validity of the evidence from other disciplines; in this regard, the sessions and the informal discussion resulting from personal encounters between different kinds of specialists are for many a real help. A great deal of enjoyment is had by all, and those who are tempted to advocate simple explanations are repeatedly reminded of the complexity of the problems they so hopefully seek to solve. It now seems almost certain that no one simple panacea is in any way adequate to explain the intriguing patterns of climatic fluctuation to which the evidence points. Almost all the many processes involved seem likely to play some essential part, small or large. The forthcoming volume of papers will provide welcome reading.

Gordon Manley

\section{EXPERIMENTAL TAXONOMY OF FLOWERING PLANTS}

A SYMPOSIUM on the experimental taxonomy of flowering plants was held at the Linnean Society on March 3. The chair at the morning session was taken by the president, Prof. C. F. A. Pantin, and at the afternoon session by Dr. W. G. Templeman.

In a brief introduction, Prof. D. H. Valentine said that the symposium should provide a good illustration of both the coherence and the wide range of experimental taxonomy. In the papers to be heard, groups at all levels, from the local population to the genus, would be treated, and the problems would be approached from a variety of points of view--genetical, ecological and taxonomic.

Dr. A. D. Bradshaw, of the University College of North Wales, Bangor, then gave his paper on "Evolution within Plant Species in Relation to Soil Mineral Factors". He pointed out that while a considerable amount is known about evolution in relation to climatic and biotic factors, soil factors have, comparatively, been neglected. This is surprising, as an examination of the differences between closely related species shows that they often possess markedly different soil preferences, which indicates that soil factors must play an important part in evolution. Experiments have been done in sand cultures on a number of common species, especially Festuca ovina and Trifolium repens. The fescues used were all of the 28-chromosome type, and selected tillers were grown in a range of solutions with varying concentra. tions of calcium. Populations from chalk and peat soils showed a markedly different response to growth; and an experiment on samples from base-rich and base-poor soils from the Breckland showed a similar difference, although the populations were morphologically identical. Trifolium repens gave the same kind of response in relation to variation in both calcium and phosphate concentrations, but the phosphate and calcium responses were not parallel. It would appear that populations of both species are physiologically differentiated in relation to their mineral nutrition; and such differentiation cannot be neglected in considering the evolutionary processes in these and other common species.

In the discussion on this paper, it was pointed out that much information of a similar kind was available for cultivated plants, notably rice, but that a great deal of it was inaccessible or not widely known.

The second paper, on "Interspecific Hybridization as an Evolutionary Stimulus in Wnothera", was given by Dr. P. H. Raven, of the Rancho Santa Ana Botanic Garden, California. Dr. Raven first described $E$. brevipes and $G$. clavaeformis, a pair of annual species which occur in arid areas in western North America. The species differ in a number of morphological characters (habit, flower colour, etc.), in habitat, and also in their floral biology. In one, the flowers open at about sunrise, in the other, in the late afternoon, and they are pollinated by different but closely related species of bees, which are highly specific to these flowers. Geographically, the species have a rather broad area of overlap, and natural hybrids are sometimes formed (the species are occasionally visited by insects other than the bees mentioned above). Both species have 14 chromosomes; 7 bivalente are formed in most cells, though occasionally rings of 4 or 6 chromosomes are observed; fertility is high. In the hybrids the multivalents are more frequent, larger rings or chains of up to 12 chromosomes being recorded; fertility is low, and only 5-15 per cent of good pollen is formed. Although most of the hybrids between the particular pair of populations studied appeared to be $F_{1}$ 's, other populations can be found (taxonomically of subspecific status) which are probably of hybrid origin. It would appear that occasional hybridization of the kind described may well play an important part in increasing the number of evolutionary pathways available, especially in areas such as this, in which considerable climatic changes have been occurring. In general, it may be said that the retention of the ability to hybridize and to form stable recombinant phenotypes may be regarded as a significant part of the adaptive system in higher plants. There was a short but active discussion of this paper, in which the evolution of pollinating mechanisms and the part played by chromosome interchanges in the genus were discussed.

The final paper in the morning session was given by Dr. N. W. Simmonds, of the John Innes Institute, on "Classification and Nomenclature in Bananas and Potatoes". Dr. Simmonds dealt with bananas first. He pointed out that we now had a good knowledge of the probable course of evolution in the group. The cultivated bananas had arisen from the diploid species Musa acuminata and $M$. balbisiana as a result of polyploidy and hybridization, and consisted of a group of sterile, parthenocarpic elones, mainly triploid in constitution. In the potatoes, the cultivated plants probably originated from wild diploid species, as yet not certainly identified, which had developed into the cultivated tetraploid species Solanum andigenum; and this in turn, introduced into Europe as a small sample some four hundred years ago, had given rise 